\title{
Controlling District Heating and Cooling Networks to Unlock Flexibility: a Review
}

\author{
Annelies Vandermeulen ${ }^{\mathrm{a}, \mathrm{b}, \mathrm{c}, *}$, Bram van der Heijde ${ }^{\mathrm{a}, \mathrm{b}, \mathrm{c}}$, Lieve Helsen ${ }^{\mathrm{a}, \mathrm{b}}$ \\ ${ }^{a}$ KU Leuven, Department of Mechanical Engineering, Celestijnenlaan 300 bus 2421, \\ 3001 Leuven, Belgium \\ ${ }^{b}$ EnergyVille, Thor Park, Waterschei, 3600 Genk, Belgium \\ ${ }^{c}$ VITO, Boeretang 200, $2400 \mathrm{Mol}$, Belgium
}

\begin{abstract}
Flexibility in district heating and cooling systems (thermal networks in general) is an important means to cope with the intermittent generation of heat and electricity as the share of renewable energy sources (RES) increases. An important source of flexibility is the thermal energy storage present in district heating and cooling networks, found in the thermal inertia of buildings, storage units and the network itself. To unlock this flexibility and to use it effectively and efficiently, a suitable control strategy is required. In this context, this paper presents a possible definition of flexibility and its sources in a thermal network. It reviews techniques to quantify flexibility and shows the need for a more advanced control strategy; moreover, it discusses the challenges involved in developing such a control strategy. Also, the literature on advanced control in thermal networks is reviewed, by making a distinction between central, distributed and hybrid control. Finally, possible future research topics are identified based on the findings.

Keywords: District Heating, District Cooling, Thermal Networks, Control, Flexibility, Thermal Energy Storage
\end{abstract}

*Corresponding author at: EnergyVille, Thor Park, Poort Genk 8310, 3600 Genk, Belgium. E-mail address: annelies.vandermeulen@kuleuven.be (A. Vandermeulen). 


\begin{tabular}{|c|c|c|c|}
\hline \multicolumn{4}{|c|}{ Nomenclature } \\
\hline $\mathrm{ADR}$ & Active Demand Response & MINLP & \multirow{2}{*}{$\begin{array}{l}\text { Mixed Integer Non-Linear } \\
\text { Problem }\end{array}$} \\
\hline \multirow[t]{2}{*}{ ATES } & Aquifer Thermal Energy & & \\
\hline & Storage & MPC & Model Predictive Control \\
\hline BTES & $\begin{array}{l}\text { Borehole Thermal Energy } \\
\text { Storage }\end{array}$ & RES & $\begin{array}{l}\text { Renewable } \\
\text { Sources }\end{array}$ \\
\hline CHP & $\begin{array}{l}\text { Combined Heat and } \\
\text { Power }\end{array}$ & $\mathrm{SoC}$ & State of Charge \\
\hline COP & Coefficient & SoS & Security of Supply \\
\hline & mance & TABS & Thermally \\
\hline DHW & Domestic Hot Water & & Building Systems \\
\hline MAS & Multi-Agent System & TES & Thermal Energy Storage \\
\hline
\end{tabular}

\section{Introduction}

Today, the use of fossil fuels becomes increasingly problematic, as they are limited resources and their use causes air pollution and other environmental problems. Furthermore, countries with a low local supply of fossil fuels are becoming increasingly dependent on the import of energy sources. This jeopardizes the Security of Supply (SoS), as the reliability of fossil fuel deliveries cannot always be guaranteed, be it due to geopolitical or other reasons. In sum, these issues call for a change in the energy system.

In previous years, researchers and politicians mostly focused on the electricity system to solve the problems mentioned above. By shifting the energy sources for electricity generation from fossil fuels to renewable energy sources (RES), they hope to mitigate these problems. This approach, however, has two major shortcomings.

Firstly, due to the increasing RES share, the stability of the electricity grid is at risk. Several RES (e.g. wind and solar) are intermittent, meaning they cannot be properly controlled, nor accurately predicted. Hence, the increasing RES share causes the balance between generation and use of electricity to become harder to maintain, thus increasing the risk of a black-out.

Secondly, this focus on the electricity system is inefficient, as buildings are 
responsible for about $40 \%$ of total energy use [1], of which space heating and domestic hot water (DHW) take up a large part. A significant portion of this heat is still generated directly from primary energy sources and does not even influence the electricity system. Furthermore, exergy considerations show that the use of high quality primary energy sources for very low temperature applications such as space heating is highly inefficient [2]. Therefore, the focus on the electricity system is too narrow, as many improvements can be made in a cheaper way when considering the whole energy system, including thermal, gas, fuel and electrical networks.

The Heat Roadmap Europe [3, 4, 5] considers thermal networks, i.e. district cooling or heating networks, to be essential to increase the efficiency of the energy system in an economic way. One of the of most important advantages of thermal networks is the ability to create flexibility by using the thermal energy storage (TES) present in the thermal network. Moreover, future district heating and cooling systems will be radically different from the systems used today. Lund et al. [6] defined the $4^{\text {th }}$ generation district heating and cooling systems, where use of both central and distributed heat/cold generation and TES is made and temperatures in the network are decreased substantially. An example of such a $4^{\text {th }}$ generation thermal network is shown in Figure 1. However, to successfully operate these advanced thermal networks, integrate them into the smart energy system and to successfully exploit the flexibility, an intelligent control strategy is required.

In this context, this paper aims to provide a detailed motivation of the need for advanced control, and to give an overview of past and possible future work.

To this end, flexibility in thermal networks is defined in Section 2 and the sources of flexibility in a thermal network are listed. Section 3 presents current control strategies of thermal networks, providing a reference for advanced control. Section 4 motivates the need for advanced control. Section 5 presents the challenges that need to be faced when developing an advanced control strategy. Section 6 gives an overview of the literature on advanced control for thermal networks. Finally, a summary is presented in Section 7.

This paper's title states that control of both district heating and cooling networks are discussed. However, literature on control of district cooling networks is scarce but, as Frederiksen and Werner [2] argue, there are great similarities between district heating and cooling networks. As such, this paper refers mainly to literature on district heating, but the conclusions are applicable to district cooling as well. 


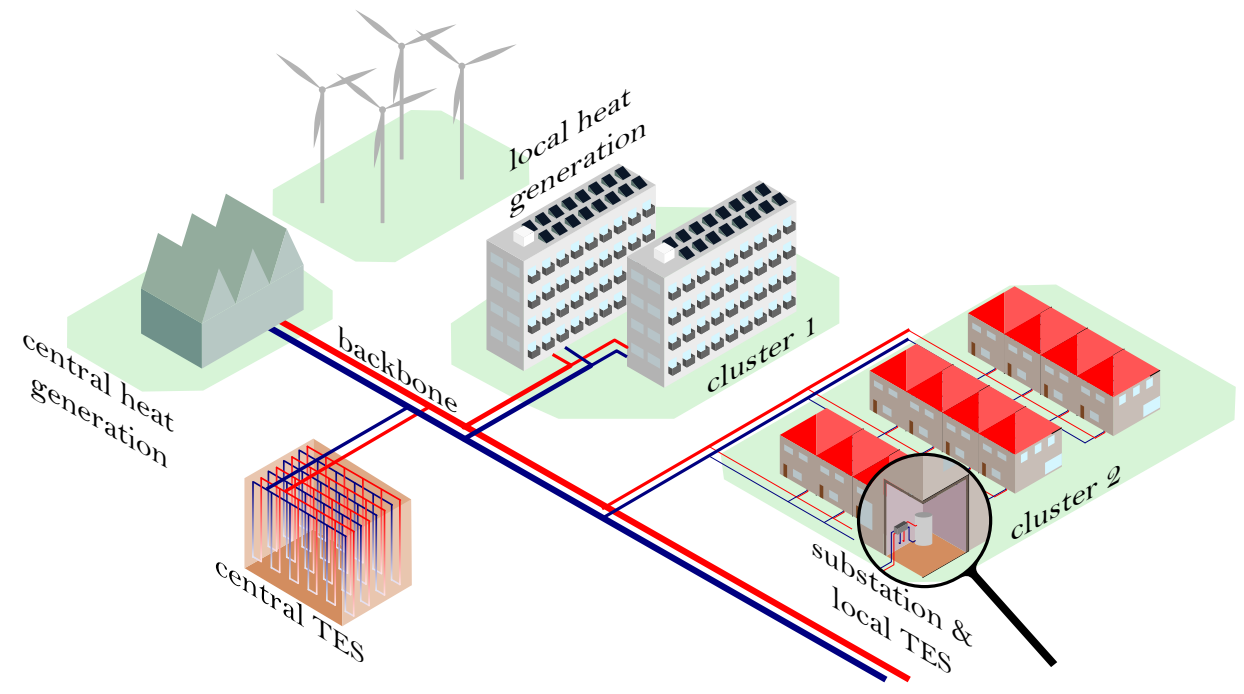

Figure 1: An example of the structure of a $4^{\text {th }}$ generation district heating system, with the heat delivered by central industrial waste heat, and local solar collectors. The TES can be found both centrally, with a borehole thermal energy storage (BTES) and distributed, in the buildings themselves and the water tanks. The different clusters of building are all connected to the backbone, which connects them to the central units.

\section{Flexibility in thermal networks}

A possible definition of flexibility is the ability to speed up or delay the injection or extraction of energy into or from a system. Speeding up or delaying entails that a comparison with a reference energy use profile is made. A complete overview of the concept of flexibility for electrical networks was given by Lund et al. [7]. Schuetz et al. [8] applied the definition of flexibility to a residential heating system. Stinner et al. [9] discussed possible flexibility indicators for thermal applications. Arteconi et al. [10] provided an overview of the Active Demand Response (ADR) potential in systems with thermal storage. They identified different types of flexibility and suggest ways in which the large flexibility potential can be unlocked.

Flexibility only requires that the system has inertia, such that the energy balance can be respected at all times. In thermal networks, thermal capacity serves as a source of thermal inertia. These capacities are found at different locations in the network, and in Figure 1;

1. the heat or cold carrier fluid,

2. thermal storage devices and 
3. the thermal inertia of the buildings to which heat or cold is supplied.

Because of the limited capacity of the first and last inertia categories, they are unable to store heat or cold over long time periods and are typically used for intra-day balancing. In systems with larger storage units, the storage capacity of the heat or cold carrier fluid is typically not used, as the same service can be provided by dedicated TES units. Depending on the size of the storage device and the technology used, this second type of inertia may in addition be used for long-term storage. Although usually, flexibility is used in a context of time scales of less than a day, this can be interpreted in a wider context as well. Seasonal flexibility is needed to enable entirely solar powered district heating systems, as the availability of sunshine and demand for heat do not coincide.

The next sections elaborate on the current use of the above mentioned types of inertia and on the quantification of flexibility.

\subsection{Network storage}

Fredriksen and Werner [11] and Basciotti et al. [12] described how a limited amount of heat or cold can be stored temporarily by raising or lowering the temperature of the water in the thermal network. This allows a certain degree of peak shaving (see Section 4.2), since the network is pre-loaded with a higher or lower temperature, which decreases the instantaneous heat load at a later stage.

However, a more frequent cycling between higher and lower temperatures might speed up material fatigue, mostly in steel pipes. Due to more frequently changing thermal stresses, cracks in the pipe wall may develop more quickly which will eventually lead to pipe failure.

\subsection{Storage in dedicated devices}

As discussed by Gadd and Werner [13], thermal energy storage systems are used in district heating and cooling systems for a number of reasons, among which are peak shaving, SoS and cost optimization. A complete discussion is presented in Section 4. The types and use of thermal energy storage typically found in district heating networks are also described by Gadd and Werner. Most systems rely on sensible heat storage (typically hot water tanks) for diurnal use. Weekly and seasonal cycles are much less common, with the exception of a number of solar heated district heating systems. 
Large storage tanks are used in e.g. Marstal, Denmark and Reykjavik, Iceland. In Marstal (DK), a $75000 \mathrm{~m}^{3}$ storage pit is coupled with a large array of solar thermal collectors, a biomass Organic Rankine Cycle and boosting heat pumps, which allow to provide sustainable heat to the adjacent town Marstal all year round [14]. An even larger pit storage of $200000 \mathrm{~m}^{3}$ was recently put into operation in Vojens (DK) [15]. In Reykjavik, about $18400 \mathrm{~m}^{3} \mathrm{~h}^{-1}$ of hot water is required for space heating during winter peaks. The geothermal heat sources typically provide $7200 \mathrm{~m}^{3} \mathrm{~h}^{-1}$, which is not enough during the coldest season. In addition to investing in an oil fired peak plant, $101000 \mathrm{~m}^{3}$ of water storage tanks were installed to bridge these extreme peaks [16].

Instead of water tanks and pits, also deeper underground layers can be used for storing heat and cold. These systems are called borehole thermal energy storage (BTES) for depths of about 50 to $150 \mathrm{~m}$ or aquifer thermal energy storage (ATES) in deeper, groundwater-carrying layers. A number of Swedish district heating and cooling systems apply ATES systems for seasonal storage [17]. Miedaner et al. [18] showed the application of a BTES system in two district heating systems in Germany and Denmark.

A particularly interesting example of a neighbourhood connected by a thermal network with underground storage and supplied mostly with solar heat is that of Drake Landing in Okotoks, Canada [19]. Solar thermal collectors have been installed on the rooftops of residential buildings in this district, supplying DHW and space heating. Surplus heat is charged into a BTES system, and this heat is recuperated during the colder season. Sibbitt et al. 20] reported yearly solar fractions well over $90 \%$ after 5 years of operation and continuing up to date.

A summary of large sensible heat storage devices combined with a CHP plant in Germany was presented by Wawer et al. [21] and for Danish district heating networks by Pedersen and Ellehauge [22]. Olsthoorn et al. [23] provided a comprehensive overview of models and applications of thermal energy storage in combination with renewable energy in district heating networks.

Although the use of energy storage usually implies a net increase in heat or cold use due to higher storage and conversion losses, Verda and Colella [24] have shown that this is not always true for combined heat and power (CHP) systems or devices characterised by state-dependent efficiencies. In a simulation of a district heating network powered by a CHP plant in Turin, Italy, they showed a net primary energy reduction of up to $12 \%$ by using a large water storage tank. This reduction is achieved by reducing the peak load, 
which avoids the use of auxiliary boilers, and by optimizing the thermal and electrical CHP efficiency using the optimal heat/electricity output ratio through operational optimization.

Instead of centrally located large thermal storage units, flexibility also emanates from smaller storage tanks dispersed over the network. Currently, many buffers for DHW are already installed. Böttger et al. [25] and Schweiger et al. 26] evaluated the power-to-heat potential in Germany and Sweden using installed DHW buffers and concluded that these systems can contribute substantially to balancing the electricity grid during oversupply of renewable energy, as will be discussed in Section 4.4. Arteconi et al. 27] study the potential of a building with a thermal energy storage vessel or a floor heating system with a heat pump. They conclude that these systems are able to flatten the elctricity use profile and thus lower peak demand.

\subsection{Building inertia}

The use of buildings for providing short-term flexibility was described in detail by Kensby et al. [28]. The temperature of the building mass is increased or decreased with respect to the setpoint, within an acceptable range. At all times, comfort requirements must be met. Kensby et al. achieved this by artificially lowering or raising the temperature setpoint of the building heating controller. Johansson et al. 29] described a possible implementation of this concept in a network using an agent-based approach, which will be discussed in more detail in Section 6.2.

Masy et al. [30] and Patteeuw [31] investigated the potential for flexible use of building inertia (also including the effect of thermal energy storage in a water buffer) on a country-wide scale. Also, the work of Reynders [32] has contributed to a better understanding of how building mass can be put to use to provide flexibility in ADR schemes. Interestingly, vad Mathiesen et al. [33] argued that instead of investing in dedicated storage systems, focus should first lie on harnessing the available flexibility in the network and connected buildings in thermal networks.

Arteconi et al. [34] identify a good flexibility potential in buildings with Thermally Activated Building Systems (TABS) from a utility perspective.

\subsection{Quantification of flexibility}

The quantification of flexibility in energy systems is a very relevant question in the framework of their control, but also a challenging one. Most of the work until recently was based on the building level, and the aggregation 
of flexibility indicators on a district or larger scale has only been tackled recently.

A specific study towards flexibility in a CHP-powered thermal network with water storage buffers was conducted by Nuytten et al. [35]. They calculated flexibility as a time span during which the injection of heat into the system can be rushed or delayed in order to shift the load. Based on the value of the indicator, it is concluded that a large centralized storage yields more flexibility than multiple smaller decentral storage systems. Furthermore, the size of the storage and the power of the CHP must be must be in tune with each other.

Stinner et al. [9] continued on the path of Nuytten et al., but extended the methodology so as to include the average power and energy shifted during a flexibility activation as new indicators. The real innovation is in their definition of a cycle efficiency, in which they compared the shifted energy versus the extra energy losses caused by shifting. This method can deal with a fixed load profile of a building and determines the flexibility of a storage device and the coupled heating system (either a heat pump or a CHP). Van der Heijde et al. [36] adapted the method of Stinner et al. such that it can also be applied to linear dynamic building models using an optimal control problem.

De Coninck and Helsen [37] quantified the flexibility in terms of the extra cost of shifting the energy use in time, thus arriving at a cost curve for flexibility as a function of the activated flexibility volume. The advantage is that these curves can be aggregated for multiple buildings. Important conclusions towards the available flexibility in residential buildings were formulated by Reynders et al. [32, 38, 39]. Reynders studied indicators for the state of charge (SoC) applied to building thermal inertia and investigated the load shifting potential for different building types. The main conclusion was that load shifting usually implies a higher energy use, and therefore he defined a storage efficiency related to load shifting actions.

Both flexibility indicators and SoC indicators can be used to express a system's ability or willingness to use or delay the use of a specific amount of heat. This is exactly what Aertgeerts et al. [40] proposed as the foundation of an agent-based controller for neighbourhoods. The SoC of water buffers was translated to a priority curve that allows aggregating the heat demand of all buildings. Consecutively, the actual heat production power is selected based on the need of all buildings. A similar analysis was performed for thermostatically controlled loads by Iacovella et al. [41]: they compared different 
relations between SoC and priority or bidding curves.

\section{Classic control of thermal networks}

This section presents classic control with the aim of providing a reference for advanced control. A first part presents the four parts of classic control of thermal networks, with an emphasis on how they are currently implemented. A second part gives a short overview of the most important advantages and disadvantages of classic control.

\subsection{The four parts of classic control}

Frederiksen and Werner [11] describe classic control of thermal networks, by splitting the control up in four parts:

Differential pressure control ensures the pressure difference between the supply and return pipe is sufficient to ensure adequate mass flow in the periphery of the network. This control is managed by the circulating pump in the thermal network.

Heat demand control ensures the comfort demands of the customers are met. This control can be found in the each of connected buildings where it is used to meet both the space heating and DHW demand.

Flow control ensures the valves in a substation are opened such that the mass flow rate is sufficiently large to deliver the demanded heat or cold to the substation.

Supply temperature control ensures the supply temperature in the network is sufficiently high (low) by injecting (extracting) the correct amount of heat. The supply temperature is determined by the use of curves that describe the relation between the outdoor temperature and the supply temperature. This set point temperature, combined with the mass flow and the return temperature of the network identifies the heat or cold that should be injected into the network.

Considering these four parts, two types of control can be distinguished. The supply temperature control and differential pressure control are both central (i.e. at operator level), whereas the flow control and heat demand control are distributed (i.e. at substation level). This distinction in controller types is used again in Section 6 to analyse the different types of advanced controllers. 


\subsection{Advantages and disadvantages of classic control}

Classic control has a very clear advantage: it is robust. It is capable of dealing with (small) errors in the system, e.g. a faulty substation, without causing large effects in the rest of the system. It is easily expandable, as the addition of new substations, heat/cold sources or TES systems do not require large changes to the controllers, as long as the size of the new systems is small compared to the size of the network.

However, it does have important disadvantages. Firstly, there is the unfair distribution of heat/cold in case of a heat deficit, as is stated by Frederiksen and Werner [11]. As the flow control is local, it only considers what happens in the substation itself. This causes an unfair distribution in case of a shortage, as users close to the heat or cold generation plant will take the energy they need, unaware that users far from the plant will experience a shortage.

Secondly, there is the limited capability of dealing with intermittent RES. As long as only a limited amount of these energy sources are connected to the network, the robustness of the classic control ensures that the integration can be done easily. However, as the amount of intermittent energy sources increases, this will no longer be sufficient, leading to an inefficient use of the energy.

\section{Motivation for advanced control in thermal networks}

Whereas classic control aims to set the heat supply equal to the heat demand, advanced control aims make them unequal by using flexibility to cut costs and environmental impacts.

In fact, continuing on the four types of control as they were introduced in Section 3, advanced control introduces a fifth type control, namely load control. As opposed to heat demand control, which focuses on meeting the comfort demands of the customers, load control aims to change the heat load of the supply in order to improve the performance of the thermal network by using flexibility. To do so, load control influences other parts of the thermal network control, being mainly flow control (to charge/discharge a TES system), and supply temperature control (by actively changing the temperatures in the network to charge/discharge the network).

This section discusses in detail in what ways advanced control can improve the energy system's performance, treating the following aspects:

1. distributing heat or cold fairly, 
2. peak shaving and valley filling,

3. optimizing the operation of heat or cold generation plants,

4. providing ancillary services,

5. enabling low energy districts,

6. enabling low supply temperatures, and

7. assisting the transition to a $100 \%$ RES energy system

\subsection{Distributing heat or cold fairly}

One of the main problems of classic control, already discussed in Section 3.2 , is the unfair distribution of heat/cold in case of a heat deficit. The principle of classic control does not allow a fair distribution of heat, whereas advanced control does have this possibility. By limiting the amount of energy that is allowed to go to each substation during a heat/cold deficit, the available energy can be divided in a fair way among the customers.

\subsection{Peak shaving and valley filling}

Peak shaving and valley filling aim to reduce the peak load and increase the base load, respectively. These are techniques that improve both the efficiency of heat/cold generation plants, and reduce investment cost. The improvement in performance can be illustrated by making the following distinction between plants:

1. Base load plants: Units that are cheap (in terms of OPEX) and invariable, i.e., they cannot easily change the amount of heat or cold they produce, nor can they be turned on or off quickly. These units provide the base load, the part of the load that is rather constant throughout the year.

2. Peak load plants: Units that are expensive (in terms of OPEX) and variable, i.e. they can easily turn on and off and can quickly change the produced heat or cold. These units provide the peak load, which only occurs a few hours per year.

This distinction clearly shows that preference is given to base load plants. However, the main disadvantage with these units is their limited variability. A possible way to mitigate this problem is to use the flexibility available in the network to decrease the variations in the load, which can be achieved by advanced control. This way the peak load is reduced and the base load is increased, as shown in Figure 2. 


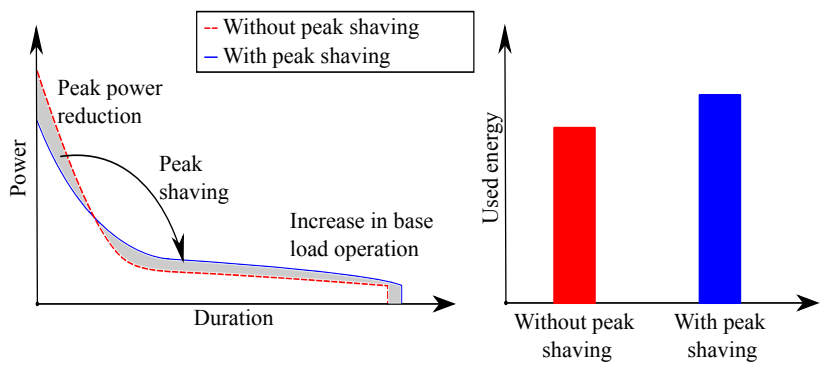

Figure 2: On the left, two load duration curves showing the consequences of peak shaving and valley filling. On the right, the corresponding energy balances.

However, as the energy balance on the right of Figure 2 shows, the amount of energy that is used to deliver the heat/cold to the customers increases when using peak shaving and valley filling. This is caused by the increased heat losses that occur when storing heat/cold in the TES systems that provide the flexibility. However, this does not imply that using peak shaving and valley filling is inefficient, as both the internal and external costs will become lower. This reduction in costs is caused, among others, by the following advantages of peak shaving and valley filling:

- The amount of peak load plants that need to be installed and the number of hours they need to run, decrease, hence reducing pollution, operational and investment costs.

- Less starts and stops of base load plants are required, decreasing the running costs of the plants and increasing their efficiency.

- Some base load plants, e.g. waste incineration plants, operate continuously with very little possibility for changing the heat output, as stated by Østergaard and Lund [42. By increasing the base load, the squandering of energy can be prevented.

- By reducing the peak load, a smaller sizing of the different components in a thermal network is possible, thereby decreasing investment costs.

Controllers that pursue peak shaving and valley filling in thermal networks use flexibility by exploiting the thermal energy storage present in the thermal network, as discussed in Section 2. Examples include controllers using the distribution network [12], the thermal inertia of buildings [28] or DHW tanks [43]. 


\subsection{Optimizing the operation of heat or cold generation plants}

Advanced control in thermal networks can improve the operation of generation plants. Here, the cases of a CHP plant and heat pump are discussed in more detail.

The optimization of a CHP plant operation can improve two aspects. Firstly, electricity sales being one of the most important sources of income for CHP plants, CHP plant operation can be based on the variable electricity price. Zhao, Holst and Arvastson 44 took this variable electricity price into account when optimizing a CHP plant, to do so they used the flexibility provided by a storage tank.

Secondly, the heat and electrical efficiency of a CHP plant can be improved by using advanced control, as it is dependent on the supply and return temperatures in the network. This aspect is discussed in more detail in Section 4.6. However, it should be noted that these concerns only relate to smaller CHP plants, not to large extraction steam cycles with high operational flexibility.

Similarly to a CHP plant, a heat pump's efficiency and profitability can be improved when using advanced control. Again, the variable electricity price strongly influences the profits of the heat pump. Furthermore, the coefficient of performance (COP) strongly depends on the heat pump's evaporator and condenser temperatures. When taking these factors into account, the performance of the heat pump can improve significantly, as shown by Verhelst et al. [45].

\subsection{Offering ancillary services}

Advanced control allows thermal networks to offer ancillary services to the electricity network, thereby increasing the profitability of the thermal network. Thermal networks can offer these services by using the links between the electricity distribution grid and the thermal network, including CHP's and heat pumps. Ancillary services that could be offered include frequency control (primary, secondary and tertiary) and voltage control.

Frequency control entails keeping the balance between generation and use of electricity on a country, or even continent scale. Voltage control entails keeping the voltage within safe limits, by balancing the generation and use of electricity on a local scale, as is illustrated by Baetens et al. [46]

Examples in which use of advanced control is made to provide ancillary services with thermal networks include the work by Salpakari et al. [47], who developed an operational optimization to incorporate intermittent RES in 
Helsinki. Additionally, Li et al. [48] optimized the dispatch of a CHP plant to accommodate electricity generation by RES.

In the future, ancillary services will gain more importance as the share of intermittent and/or distributed energy sources is increasing.

\subsection{Enabling low-energy districts}

The principle of low-energy districts is to keep the generated energy vectors (be it electricity, heat or cold) within the district by using or storing them locally, thus minimizing interaction with the respective main grids. An example of such a system is shown in Figure 1, where different clusters (or districts) are connected to the backbone, i.e. the main line that transports heat/cold over longer distances. This configuration offers several advantages [49]; as a result of the local energy use, the backbone of the network, is loaded less. This can either reduce the transmission losses in case of an equal number of loads connected to the backbone, or it allows increasing the number of loads without increasing the transmission losses or the capacity of the backbone. These low-energy districts also encourage the integration of distributed energy sources, by e.g. micro-CHP, solar panels or solar collectors.

When larger amounts of distributed, intermittent RES are installed in these districts, an active coordination of charging and discharging the different storage systems will be necessary to deal with the difference between generation and demand of energy within the district. Here, advanced control comes into play, which can exploit the local flexibility to deal with this difference.

The controller developed in the H2020 STORM project [49] (explained in more detail in Section 6.3 can ensure locally generated heat is used locally and as little heat as possible needs to be imported from the backbone.

\subsection{Enabling low supply temperatures}

The newest generation of thermal networks [6] is characterized by lower supply temperatures (or higher in case of district cooling networks). A lowered supply temperature resulted in many benefits, including a decrease in distribution losses, an increased efficiency of heat pumps and CHPs in the network and access to low temperature heat sources, such as waste heat. One

of the methods available to achieve these lower temperatures is the use of advanced control. Falkvall and Nilsson [50, reduced the supply temperature in a district heating network by $5{ }^{\circ} \mathrm{C}$ by using advanced control. Benonysson 
[51] and Saarinen [52] both used advanced control to lower supply temperatures, leading to an increased CHP efficiency.

However, it should be noted that the main contribution to the successful temperature reductions in these papers is caused by the classic control's tendency to apply somewhat higher supply temperatures to avoid low differential pressures caused by high mass flows.

Additionally, lower return temperatures are the general cause of a lower supply temperature. This reduction in return temperature can be obtained by fewer errors in the network, longer substation heat exchangers and lower customer temperature demands. A detailed overview of techniques to achieve lower return temperatures is given by Gadd and Werner [53].

\subsection{Assisting the transition to a 100\% RES energy system}

Advanced control can, when it has been developed and implemented, serve as an enabling technology to support the transition to an energy system with $100 \%$ RES, thanks to, first and foremost, the aspects discussed above. Additionally, the advanced controller can also be used by policy makers to actively monitor the transition to $100 \%$ RES. For example, the intelligence in the controller allows gradually reducing the share of heat that is delivered by fossil fuel fired boilers.

\section{Challenges of control in thermal networks}

Section 4 motivated why the development and implementation of an advanced control strategy is beneficial. However, many challenges need to be faced during its development, four of which are treated in detail:

1. size of the thermal network,

2. prediction uncertainties,

3. complex dynamics and,

4. flexibility quantification.

\subsection{Large networks}

Advanced control needs measurement data about the state of the network, including:

- the valve positions,

- the mass flow rates and temperatures in the network, 
- the state of the buildings,

- the state of the heat or cold generation plants, and

- the state of charge of the thermal energy storage units.

Depending on the control strategy, the frequency of the measurement data could be as large as multiple samples per hour. Furthermore, the size of a thermal network can range from a street to an entire region, as can be observed in Nussbaumer's study of district heating systems in a number of IEA member countries [54].

To make, collect and process all these measurements, many sensors need to be installed and a communication network needs to be set up, resulting in large initial investments to install an advanced controller. Furthermore, the operation and maintenance of this information network is significant and is a serious disadvantage of advanced control. There are, however, some options to mitigate the costs of monitoring and controlling thermal networks. By using estimators, the amount of measurements needed, is reduced [55]. Furthermore, the controller can be developed in such a way that it reduces the amount of information to be sent across the network. By introducing an agent-based controller with a hierarchical structure (see Section 6.2), the information flows can be reduced significantly [56].

A remark regarding the costs of a communication network is the aim of the EU to install smart meters in all buildings connected to the electricity system. If these smart meters can also monitor thermal energy use and temperatures in the buildings, the investment costs for the communication network can be shared by the electricity, heat and gas network.

\subsection{Prediction uncertainties}

To control thermal networks, different predictions are needed to have a control strategy that can anticipate future events. Two types can be distinguished, namely the predictions coming from external sources and predictions that are generated by the controller.

The predictions originating from external sources include:

- The variable electricity and heat/cold prices that are used to optimize the operation of heat/cold generation plants.

- The weather which is needed to optimize the operation of heat pumps and to determine the heating and cooling demand. 
- The user behaviour that is used to determine the heating and cooling demand. However, these predictions can also be generated by the controller using e.g. stochastic occupancy profiles [57].

Also, the controller needs to generate an accurate forecast of the heating and cooling demand using the predictions from external sources. Two factors influencing the demand are the need for space heating and cooling, and DHW. A good first order approximation entails a linear variation with the outdoor temperature for space heating and cooling and a constant value for DHW use [58].

Different approaches can be used when forecasting heating and cooling demand. Here, a distinction is made by the type of model. A choice can be made between three different categories, namely white-, grey- or blackbox models. Table 1 presents a comparison of the structure of the models (top part) and of the properties of the models (bottom part). Below, the comparison is presented in more detail.

A white-box model is based solely on physical laws and parameters. Thus, no measurement data are used when determining the relation between the in- and outputs of the system, only the knowledge of how the system is built, is used.

A black-box model is the other extreme: here, only statistical methods are used to determine the relations between the in- and outputs. Hence, plenty of measurements are required to generate this kind of model.

A grey-box model combines features of both white and black-box models. Thus, it bases the model on physical laws, but determines the parameters in the model by using statistical methods and measurement data to ensure an optimal fit with the actual system.

Considering their properties, the most important ones showing a clear difference between the different models are:

1. Physical insight: Does the model provide a good insight in the dynamics of the system?

2. Number of measurements: Does the model generation require less measurements and hence a lower installation cost?

3. Plug-and-play: Can a new model easily be obtained once the model framework has been developed or is expert knowledge required every time a new system needs to be modelled? 
Table 1: A comparison of white-, grey- and black-box models. Plus-signs indicate a better performance regarding the property in question, where minus-signs indicate a lesser performance.

\begin{tabular}{lccc}
\hline & White & Black & Grey \\
\hline Laws & Physical & Statistical & Physical \\
Parameters & Physical & Statistical & Statistical \\
\hline Physical insight & ++ & -- & + \\
$\mathrm{N}^{\circ}$ of measurements & ++ & -- & + \\
Plug-and-play & -- & ++ & ++ \\
\hline
\end{tabular}

\subsection{Complex dynamics}

The controller needs to understand and predict the behaviour of the system. To do so, it requires accurate but simple models describing the different parts of the network and their interactions. A short discussion on models suited for the heating or cooling demand forecasts was already given in Section 5.2. This section treats the modelling of the distribution network, storage and generation units in more detail.

The distribution network heavily influences the control problem due to the travelling time of thermal energy through the pipes, especially in geographically large networks. Therefore, the determination of the travelling time is an important research topic, already thoroughly treated in the literature.

Often simplifications are made to model the distribution network; Benonysson [59] stated that, although the dynamics mostly concern pressure and temperature variations, the pressure variations can often be neglected or simplified, as they travel about 1000 times faster than variations in temperature. Typically, the pipes in the network are modelled with pseudo-dynamic models, in which the propagation of pressure waves is assumed to be instantaneous. A complete overview of existing methods and assumptions is given by Pálsson et al. [60]. A comprehensive overview of district heating pipe models is presented by van der Heijde et al. [61].

Additionally, in the case of large thermal networks, the network models can be simplified by aggregation. Here, a model of an extensive system or subsystem is simplified while retaining its properties. A review of methods for aggregation of district heating networks is discussed by Larsen, Bøhm and Wigbels [62].

Storage units also require detailed and accurate modelling to determine 
their state of charge and thermal behaviour. Regarding storage in dedicated services (see Section 2.2), Verda and Colella modelled a $1000 \mathrm{~m}^{3}$ stratified, cylindrical tank [24]. De Ridder and Coomans used a grey-box model to represent the thermodynamic behaviour of a water storage vessel [63], which can be used to determine its state of charge. Additionally, Verhelst and Helsen made a linear dynamic model for a borefield [64]. For thermal storage state characterization in buildings, Reynders [32] and van der Heijde et al. 65] proposed different state of charge indicators.

The heat or cold generation units also show complex dynamics. There are many kinds of generation units in a thermal network, including heat pumps, CHPs, gas boilers, absorption chillers, solar collectors, industrial waste heat, waste incineration and geothermal sources. Each of these is different with respect to efficiency, availability, start and stop times, etc. and needs to be represented by an appropriate dynamic model.

\subsection{Quantification of flexibility}

As already discussed in Section 2.4, quantification of flexibility is a very relevant question in the field of thermal network control. Different ways to quantify flexibility have been treated in the literature [66], but, and especially regarding the thermal inertia of buildings, a method to determine and

represent the available flexibility in a simple, accurate and concise manner is still lacking.

\subsection{Conclusion}

The discussions in Sections 5.1, 5.2, 5.3 and 5.4 show the main challenges in developing a good control strategy for a thermal network. These discussions lead to the identification of several research questions, the answers to which can lead to an easier implementation of advanced control strategies. These research questions include:

1. What is the influence of prediction errors on the performance of the controller?

2. How to develop accurate models, adequate for operational optimization of thermal networks (see Section 6.1.1)?

3. How do the different kinds of models (white-, grey- or black-box models) compare when predicting the heating or cooling demand in a control context? 
4. What is the minimum amount of sensors required to determine the state of the thermal network and where should they be placed?

5. How to best quantify flexibility in thermal networks and how to implement this quantification in a controller?

6. Which sensors are needed to accurately determine the flexibility in a building?

\section{Overview of controllers in thermal networks}

This section reviews the literature on advanced controllers for thermal networks. Besides this paper, Kosek et al. [67] presented a comprehensive overview of the different possibilities for demand side management control schemes. Even though their review concerns control schemes for buildings, the control principles explained there can be easily applied to thermal networks.

The review of controllers for thermal networks in this paper is split up in three different control configurations, also shown in Figure 3.

1. The control of the different entities is done at a central level with one large central unit deciding the actions of all entities to control the system. This option is further discussed in Section 6.1.

2. The control of the different entities is distributed. All the entities will, through cooperation or competition, decide the actions they will undertake. This option is treated in Section 6.2.

3. The control of the different entities is done at both central and distributed level. Hence, in this paper the term hybrid control is used. This option is presented in Section 6.3.

\subsection{Central control}

A first method to control a thermal network is central control. Here, one central unit receives all measurements and information on the network and uses this knowledge combined with predictions to determine the required actions in the network. A possible configuration of a central controller is shown in Figure 3 .

The literature on central control for thermal networks can be split up in three groups. There is the literature on operational optimization, in which

the control of the thermal network is optimized (Section 6.1.1). One step 
further is model predictive control (MPC), in which the result of the operational optimization is applied to control the thermal network (Section 6.1.2). Additionally, literature that concentrates on central control techniques other than operational optimization, can be found as well (Section 6.1.3).
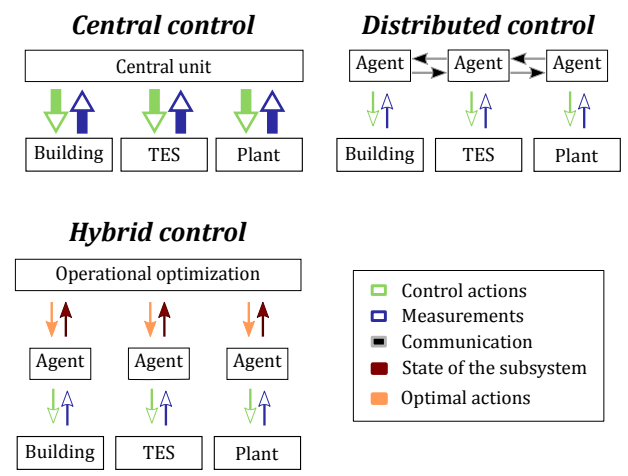

Figure 3: Examples for each of the three possible control configurations in a thermal network. The thickness of the arrows indicate the size of the information flows.

\subsubsection{Operational Optimization}

In operational optimization the control of a system is optimized in the short term, i.e. a few hours to a few days ahead. This optimization can be optimal with respect to different objectives, e.g. a minimization of peak power (see Section 4.2), a minimization of cost (see Section 4.3), etc. By including a model of the thermal network, describing the behaviour of the different components and the system, and considering predictions of thermal energy demand, weather, and energy price, the optimal control actions can be decided.

An older example of operational optimization for thermal networks is Benonysson's work [59]. Benonysson showed, through the results of the operational optimization, that optimal control of thermal networks calls for a very active control of the supply temperature.

Numerous studies have based their work on Benonysson's operational optimization. Bøhm et al. 68. provided a summary of models suitable for operational optimization. Leśko and Bujalski [69] developed operational optimization of a district heating network but focused on thermal load shifting by using the thermal inertia of buildings.

One of the difficulties in developing operational optimization is the inclusion of the time delays (see Section 5.3) in the optimization. Benonysson 


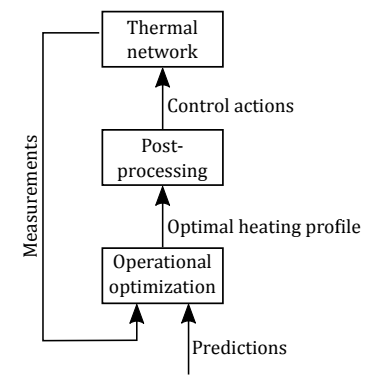

Figure 4: The principle of model predictive control for a thermal network.

coped with this problem by introducing the node method. Laakkonen et al. [70], on the other hand, optimized the control of district heating networks by using delay distributions.

In operational optimization of thermal networks, the optimization problem is a mixed integer non-linear problem (MINLP). Here, the non-linearity is caused by the time delays in the network and the integers are required to model the on/off status of the heat or cold generation plants. However, no efficient solvers exist for an MINLP. To mitigate this problem, Ikonen et al. [71] used permutational invariance to simplify the optimization problem and Runvik et al. [72] split the optimization in two sub-optimizations, both of which have efficient solvers:

1. A unit commitment problem: By approximating the behaviour of the district heating network with a linear model and using this to decide the on/off status of the different production units, this first optimization problem turns into a mixed integer linear problem.

2. An economic dispatch problem: A detailed, non-linear model of the district heating network is now optimized. With the on/off status of the production plants already calculated in the previous step, the optimization problem becomes a non-linear optimization.

\subsubsection{Model Predictive Control}

One step further than operational optimization is model predictive control (MPC). Whereas operational optimization is an off-line optimization, MPC is an on-line optimization, i.e. it applies the optimal control profile to the thermal network, as shown in Figure 4. It is a robust form of control, as it compensates prediction errors and model mismatches in the operational optimization through the feedback of the network itself. 
Examples include the work of Saarinen [52], who developed a controller to increase the profits of a CHP plant. She compared the MPC strategy with the classic method, as presented in Section 3, and concludes that plenty of savings $(200,000$ SEK or about $€ 21,000$ per year) are possible through the use of MPC. To deal with the non-linear behaviour of the district heating system, Grosswindhager et al. [73] developed another type of MPC, in particular a fuzzy direct matrix controller. A final example is the work by Verrilli et al. 74. They developed an MPC for a district heating network, focusing on the flexibility that can be provided by both TES and other flexible loads.

\subsubsection{Other central control approaches}

All controllers discussed in Sections 6.1.1 and 6.1.2 used optimization problems to determine the actions in the thermal network. In this section, the literature on central controllers that do not use operational optimization is presented.

Central control for thermal networks already dates back to the eighties with the work of Österlind [75], as described by Kensby [76], and Wernstedt and Johansson [77]. Österlind implemented a direct load control system in a district heating network in which the controller sends commands from one central location to the buildings in the network. In this specific case, the controller managed the heat deliveries to every building to cope with heat shortages in the system.

However, unlike the central configuration shown in Figure 3, this controller could not receive measurements from the buildings. Consequently, the controller could not ensure the heat demand of the end users was met. Accordingly, Österlind argued that a minimum requirement for a central controller for thermal networks is a two-way communication link, as is shown in Figure 3 .

Pálsson [78] developed a controller to decrease the supply temperature in a district heating system. This controller used two types of sub-controllers; firstly, a flow sub-controller was used which selects the highest mass flow rate possible without violating the constraints. Secondly, supply temperature sub-controllers were used, each of which selects the minimum supply temperature possible to ensure a sufficiently high temperature at a representative point in the network. Other examples of central controllers not using operational optimization exist. Basciotti et al. [12] aimed to reduce the peak power in a district heating network, as discussed in Section 4.2, by developing a PID controller that uses the network as thermal energy storage. 
Papakonstantinou et al. [79] developed a controller that assesses the lowest temperature it could send to a district heating network, through prediction of the heat demand and calculation of the time delays in the network. More specifically, by grouping customers with equal temperature propagation delays, the required supply temperature to meet the demand in each of these groups can be determined.

\subsection{Distributed control}

The second possible configuration to control a thermal network is by using distributed control. Here, many smaller points of intelligence spread throughout the entire network are used to control the thermal network. An example of a possible distributed control configuration is illustrated in Figure 3 .

One of the simplest forms of distributed control is the use of a price signal as an input to the end users. Van Deventer, Gustafsson and Delsing [80. showed that with even such a simple scheme, the peak load in the thermal network can be significantly reduced.

An often implemented form of distributed control is a multi-agent system (MAS) in which all subsystems of the overall system are represented by an agent, as is depicted in Figure 3. Such an agent monitors the state of its subsystem and ensures the demands of the customers, e.g. comfort demands for residential buildings, are met. Furthermore, the agent communicates with the other agents before it decides its actions. Wernstedt and Davidsson [56] stated that a multi-agent system is a suitable controller for a thermal network as these networks are modular, decentralised, changeable, ill-structured and complex. They also argued that the use of a multi-agent system can increase the robustness, efficiency, flexibility, openness and scalability of the control problem.

Wernstedt and Johansson [77] used a configuration similar to the one shown in Figure 3, but implemented only two kinds of agents instead of four. More specifically, the end users were all represented by consumer agents which sell load shedding to the producer agents, representing the heat gen-

eration plants. Furthermore, the consumer agents have a limited amount of load shedding they can sell, as they need to keep the temperatures in the buildings within the comfort boundaries. This resulted in a reduction of the daily fluctuation in the heat load, while still complying with the end users' demands.

Similarly to Wernstedt and Johansson, Geysen et al. [81] developed an MAS with consumer and producer agents. However, Geysen et al. applied 
the principle of MAS to the combination of a district heating network and an electricity network. They looked for an economically optimal control by letting the agents generate electrical and thermal power bid surfaces. These surfaces show the willingness to buy/sell either electricity or heat as a function of the price of electricity and heat for one subsystem. By combining the surfaces from all agents, both producers and users of electricity and heat, a market equilibrium can be found. Subsequently, this market equilibrium can be used by the agents to determine the actions to be taken.

\subsection{Hybrid control}

The third control configuration for a thermal network combines the first two methods, hence the name hybrid control. A hybrid controller solves an operational optimization centrally and then distributes the results of the optimal load profile to the distributed agents, as shown in Figure 3 .

A first example of a hybrid controller was presented by Johansson and Wernstedt [29]. Here, initially, an operational optimization is solved to determine the heat load that maximizes profits. The optimal load profile and its value (i.e. the profit that can be made by using it) is then passed on to the producer agents who try to sell it to the building agents. These building agents are responsible for two aspects, (1) to meet the end users' demands and (2) to maximize their profits by buying heat from the producer agents. As such, the more they can adapt themselves to the optimal heat load profile by using the flexibility available in the building, the more profit both the producer agents and the consumer agents can make.

Another example of hybrid control is the one developed by Bünning et al. [82. They present a multi-agent controller for a low temperature district heating and cooling network that includes a central supply temperature optimization. The agents representing the heat or cold generation divide the required heat/cold capacity amongst themselves, keeping the both the warm and cold line at a sufficiently high/low temperature.

A final example is the controller developed in light of the EU H2020 STORM-project [49]. This controller is also based on an MAS but expands this principle with three modules that are implemented centrally:

1. The forecast module predicts the heat/cold demand by using modelfree, machine learning [83], i.e. a black-box model.

2. The planning module determines the optimal heat/cold load profile based on forecasts made by the forecast module. This profile can be 
optimal with respect to peak shaving (see Section 4.2), cost minimization/profit maximization (see Section 4.3) or cell balancing, where the generated energy is used within small clusters of buildings (see Section 4.5).

3. The tracker module communicates with the agents to ensure the total load of the network matches the optimal load profile as good as possible.

\subsection{Comparison and conclusion}

When studying the literature on control of thermal networks, one can find a clear evolution in the choice of control strategy. Central control, and more specifically operational optimization, is the oldest method with plenty of literature available on the subject. However, the technique requires large amounts of data to be gathered at a central location (as was also indicated in Figure 3). Hence, a following step in the literature was to implement a multiagent system that is suited for the large, modular and changeable thermal networks. However, these multi-agent systems without a strong central unit do not lend themselves to take the dynamics of the network into account. Therefore, recent literature focuses on hybrid control, which combines the operational optimization of the central controller with the multi-agent system. This results in a controller that can cope with both the large, changeable and modular thermal network and its dynamics.

The use of a hybrid controller offers other advantages. Firstly, through the use of agents, who monitor the subsystems, the quality of service to the customers can be guaranteed. In the case of central control, the interests of the individual customer are threatened to be forgotten for the sake of the whole system, thereby risking unsatisfied customers.

Secondly, the central operational optimization (present in both the central and hybrid configuration) can be simplified by using an aggregated model of the thermal network. This offers a clear advantage; through aggregation, the operational optimization only requires aggregated information of the system in the network, resulting in a better privacy protection of the customers.

It should be noted that there is extensive literature on operational optimization, yet this was not the case with distributed and hybrid control. It seems that, regarding MAS in thermal networks, still plenty of research is required. 


\section{Summary}

This paper reviewed the literature concerning the exploitation of flexibility in district heating and cooling networks through control.

A first part dealt with the definition of flexibility, where to find flexibility in thermal networks and how to quantify it. Firstly, flexibility was defined as the ability to speed up or delay the injection or extraction of energy into or from the system. Secondly, the sources of flexibility in thermal networks are abundant and can be found in thermal energy storage or thermal inertia of 1) the network itself, 2) the buildings and 3) dedicated storage units. Thirdly, concerning the quantification of flexibility, the literature provides some possible definitions, but, still, to allow the use of flexibility indicators in operational control further research is required.

A second part has shown that there is indeed a need for an advanced control strategy. In particular, if this control strategy is well designed, it cannot only avoid an unfair distribution of heat/cold, but it can also unlock the flexibility to offer peak shaving and ancillary services, increase the efficiency of heat (and cold) production plants, decrease (or increase) the supply temperature in the district heating (or cooling) networks, enable zero-energy districts, and aid in the transition to a $100 \%$ renewable energy system.

A third part discussed the challenges in developing an advanced controller. This discussion revealed the most important challenges including the handling of prediction uncertainties, the complex dynamics specific to thermal networks and the size of the networks. Each of these challenges still calls for additional research to ensure an efficient and effective control of thermal networks.

A final part gave an overview of the literature on advanced control in order to show the status of current research. Three approaches in the literature can be identified. Firstly, central control, can be used, with one central point of intelligence receiving all information and making all decisions which are often based on operational optimization. Secondly, the use of distributed control, in particular, agent-based control, is also a possibility. Here, the controller consists of several agents, each deciding the local actions to be taken based on the information they receive from external sources, from a central unit or from the other agents. Finally, an option that is gaining increasing interest is the use of hybrid control. This controller combines the features of central and distributed control, hence with a central unit using operational optimization to decide the global actions to be taken in 
the system, which are then distributed to the agents. This controller looks very promising and deserves further attention.

\section{Acknowledgements}

This study is part of the project "Towards a sustainable energy supply in cities". This project is supported by the European Union, the European

Regional Development Fund ERDF, Flanders Innovation \& Entrepreneurship and the Province of Limburg (Belgium). The research of Bram van der Heijde and Annelies Vandermeulen is furthermore funded through a VITO PhD Fellowship.

\section{References}

[1] European Parliament. EU directive on the energy performance of buildings (recast). (2010/31/EU), 19 May 2010.

[2] Svend Frederiksen and Sven Werner. District heating and cooling. chapter 2, pages 25-27. Studentlitteratur, 2013.

[3] David Connoly, Brian Vad Mathiesen, Poul Alberg Østergaard, Bernd Möller, Steffen Nielsen, Henrik Lund, Urban Persson, Sven Werner, Jan Grözinger, Thomas Boermans, Michelle Bosquet, and Daniel Trier. Heat Roadmap Europe 2050: Second pre-study for the EU2\%. Aalborg, 2013. ISBN 9788791404481.

[4] David Connoly, Brian Vad Mathiesen, Poul Alberg Østergaard, Bernd Möller, Steffen Nielsen, Henrik Lund, Daniel Trier, Urban Persson, Daniel Nilsson, and Sven Werner. Heat roadmap Europe 2050: First pre-study for the EU-2\%. Aalborg, 2013. ISBN 9788791404481.

[5] David Connolly, Kenneth Hansen, David Drysdale, Henrik Lund, Brian Vad Mathiesen, Sven Werner, Urban Persson, Bernd Möller, Ole Garcia Wilke, Kjell Bettgenhäuser, Willemijn Pouwels, Thomas Boermans, Tomislav Novosel, Goran Krajačić, Neven Duić, Daniel Trier, Daniel Møller, Anders Michael Odgaard, and Linn Laurberg Jensen. Stratego. Enhanced Heating and Cooling Plans to Quantify the Impact of Increased Energy Efficiency in EU Member States. Translating the Heat Roadmap Europe Methodology to Member State Level. Aalborg, 2015. 
[6] Henrik Lund, Sven Werner, Robin Wiltshire, Svend Svendsen, Jan Eric Thorsen, Frede Hvelplund, and Brian Vad Mathiesen. 4th generation district heating (4GDH): Integrating smart thermal grids into future sustainable energy systems. Energy, 68:1 - 11, 2014. ISSN 0360-5442. doi: http://dx.doi.org/10.1016/j.energy.2014.02.089.

[7] Peter D. Lund, Juuso Lindgren, Jani Mikkola, and Jyri Salpakari. Review of energy system flexibility measures to enable high levels of variable renewable electricity. Renewable and Sustainable Energy Reviews, 45:785-807, 2015. ISSN 13640321. doi: 10.1016/j.rser.2015.01.057.

[8] Philipp Schuetz, Damian Gwerder, Lukas Gasser, Ludger Fischer, Beat Wellig, and Jörg Worlitschek. Thermal storage improves flexibility of residential heating systems for smart grids. In Proceedings of the 12th IEA Heat Pump Conference, pages 1-9, Rotterdam, the Netherlands, 2017.

[9] Sebastian Stinner, Kristian Huchtemann, and Dirk Müller. Quantifying the operational flexibility of building energy systems with thermal energy storages. Applied Energy, 181:140-154, nov 2016. ISSN 03062619. doi: 10.1016/j.apenergy.2016.08.055.

[10] A. Arteconi, N.J. Hewitt, and F. Polonara. State of the art of thermal storage for demand-side management. Applied Energy, 93:371 - 389, 2012. ISSN 0306-2619. doi: https://doi.org/10.1016/j.apenergy.2011. 12.045 .

[11] Svend Frederiksen and Sven Werner. District heating and cooling. chapter 10, pages 469-481. Studentlitteratur, 2013.

[12] Daniele Basciotti, Florian Judex, Olivier Pol, and Ralf-Roman Schmidt. Sensible heat storage in district heating networks: a novel control strategy using the network as storage. In Conference proceedings of the 6th International Renewable Energy Storage Conference IRES, Berlin, Germany, 2011.

[13] Henrik Gadd and Sven Werner. Thermal energy storage systems for district heating and cooling. In Advances in Thermal Energy Storage Systems, chapter 18, pages 467-478. Woodhead Publishing, 2015. ISBN 9781-78242-088-0. doi: http://dx.doi.org/10.1533/9781782420965.4.467. 
[14] Thomas Pauschinger and Thomas Schmidt. Solar unterstützte KraftWärme-Kopplung mit saisonalem Wärmespeicher. Euro Heat $\&$ Power, 2013.

[15] Henrik Lund, Poul Alberg Østergaard, David Connolly, Iva Ridjan, Brian Vad Mathiesen, Frede Hvelplund, Jakob Zinck Thellufsen, and Peter Sorknæs. Energy Storage and Smart Energy Systems. International Journal of Sustainable Energy Planning and Management, 11: 3-14, 2016. ISSN 22462929. doi: 10.5278/ijsepm.2016.11.2.

[16] Einar Gunnlaugsson, Gretar Ívarsson, and Jakob S. Fridriksson. 85 Years of Successful District Heating in Reykjavík, Iceland. In Proceedings World Geothermal Congress 2015, pages 19-25, Melbourne, Australia, 2015. Reykjavík Energy.

[17] Olof Andersson. Aquifer thermal energy storage (ATES). In Thermal Energy Storage for Sustainable Energy Consumption, pages 155-176. Springer Netherlands, Dordrecht, 2007. doi: 10.1007/ 978-1-4020-5290-3_8.

[18] Oliver Miedaner, Dirk Mangold, and Per Alex Sørensen. Borehole thermal energy storage systems in Germany and Denmark - Construction and operation experiences. In The 13th International Conference on Energy Storage, pages 1-8, Greenstock Beijing, 2015.

[19] Bruce Sibbitt, Doug McClenahan, Reda Djebbar, Jeff Thornton, Bill Wong, Jarrett Carriere, and John Kokko. The Performance of a High Solar Fraction Seasonal Storage District Heating System Five Years of Operation. Energy Procedia, 30:856-865, jan 2012. ISSN 18766102. doi: 10.1016/j.egypro.2012.11.097.

[20] Leidos Canada. Drake Landing Solar Community - Annual Performance Monitoring Report for 2013-2014. Technical Report December, Ontario, 2014.

[21] Tim Wawer, Stephan Hohmeier, and Hannes Seidl. Steigerung der Flexibilität und Effizienz von Kraft-Wärme-Kopplungsanlagen durch die Kombination mit Wärmespeichern. Technical report, Deutsche EnergieAgentur, Berlin, 2012. 
[22] T. Pedersen and K. Ellehauge. Solar heat storages through thermal storage in district heating networks. Energinet.dk, project no. 2006-26750, 2007.

[23] Dave Olsthoorn, Fariborz Haghighat, and Parham A. Mirzaei. Integration of storage and renewable energy into district heating systems: A review of modelling and optimization. Solar Energy, 136:49-64, 2016. doi: 10.1016/j.solener.2016.06.054.

[24] Vittorio Verda and Francesco Colella. Primary energy savings through thermal storage in district heating networks. Energy, 36(7):4278 - 4286, 2011. ISSN 0360-5442. doi: http://dx.doi.org/10.1016/j.energy.2011.04. 015 .

[25] Diana Böttger, Mario Götz, Nelly Lehr, Hendrik Kondziella, and Bruckner Thomas. Potential of the Power-to-Heat Technology in District Heating Grids in Germany. Energy Procedia, 46:246-253, 2014. ISSN 18766102. doi: 10.1016/j.egypro.2014.01.179.

[26] Gerald Schweiger, Jonatan Rantzer, Karin Ericsson, and Patrick Lauenburg. The potential of power-to-heat in swedish district heating systems. Energy, 137:661-669, 2017. ISSN 0360-5442. doi: http://dx.doi.org/10. 1016/j.energy.2017.02.075.

[27] A. Arteconi, N. J. Hewitt, and F. Polonara. Domestic demand-side management (DSM): Role of heat pumps and thermal energy storage (TES) systems. Applied Thermal Engineering, 51(1-2):155-165, 2013. ISSN 13594311. doi: 10.1016/j.applthermaleng.2012.09.023.

[28] Johan Kensby, Anders Trüschel, and Jan-Olof Dalenbäck. Potential of residential buildings as thermal energy storage in district heating systems results from a pilot test. Applied Energy, 137:773 - 781, 2015. ISSN 0306-2619. doi: http://dx.doi.org/10.1016/j.apenergy.2014.07.026.

[29] Christian Johansson, Fredrik Wernstedt, and Paul Davidsson. Distributed thermal storage using multi-agent systems. In International Conference on Agreement Technologies, Dubrovnik, Croatia, 2012.

[30] Gabrielle Masy, Emeline Georges, Clara Verhelst, Vincent Lemort, and Philippe André. Smart grid energy flexible buildings through the use of 
heat pumps and building thermal mass as energy storage in the Belgian context. Science and Technology for the Built Environment, 21(6):800811, aug 2015. ISSN 2374-4731. doi: 10.1080/23744731.2015.1035590.

[31] Dieter Patteeuw. Demand response for residential heat pumps in interaction with the electricity generation system. PhD Thesis, KU Leuven, 2016.

[32] Glenn Reynders. Quantifying the impact of building design on potential of structural storage for active demand response in residential buildings. PhD Thesis, KU Leuven, Belgium, 2015.

[33] Brian Vad Mathiesen, David William Drysdale, Henrik Lund, Susana Paardekooper, Iva Ridjan, David Connoly, Jakob Zinck Thellufsen, and Jens Stissing Jensen. Future Green Buildings. Aalborg, 2016.

[34] A. Arteconi, D. Costola, P. Hoes, and J.L.M. Hensen. Analysis of control strategies for thermally activated building systems under demand side management mechanisms. Energy and Buildings, 80:384-393, sep 2014. ISSN 03787788. doi: 10.1016/j.enbuild.2014.05.053.

[35] Thomas Nuytten, Bert Claessens, Kristof Paredis, Johan Van Bael, and Daan Six. Flexibility of a combined heat and power system with thermal energy storage for district heating. Applied Energy, 104:583-591, apr 2013. ISSN 03062619. doi: 10.1016/j.apenergy.2012.11.029.

[36] Bram van der Heijde, Maarten Sourbron, F.J. Vega Arance, Robbe Salenbien, and Lieve Helsen. Unlocking flexibility by exploiting the thermal capacity of concrete core activation. Energy Procedia, 135:92-104, October 2017. ISSN 18766102. doi: 10.1016/j.egypro.2017.09.490.

[37] Roel De Coninck and Lieve Helsen. Quantification of flexibility in buildings by cost curves Methodology and application. Applied Energy, 162: 653-665, jan 2016. ISSN 03062619. doi: 10.1016/j.apenergy.2015.10.114.

[38] Geert Reynders, Thomas Nuytten, and Dirk Saelens. Potential of structural thermal mass for demand-side management in dwellings. Building and Environment, 64:187-199, 2013. ISSN 03601323. doi: 10.1016/j.buildenv.2013.03.010. 
[39] Glenn Reynders, Jan Diriken, and Dirk Saelens. A generic quantification method for the active demand response potential of structural storage in buildings. In 14 th International Conference of the International Building Performance Simulation Association (IBPSA), Hyderabad, India, March 2016.

[40] Arnout Aertgeerts, Bert Claessens, Roel De Coninck, and Lieve Helsen. Agent-Based Control of a Neighborhood : a Generic Approach By Coupling Modelica With Python. In 14th Conference of International Building Performance Simulation Association, pages 456-463, Hyderabad, India, 2015.

[41] Sandro Iacovella, Frederik Ruelens, Pieter Vingerhoets, Bert Claessens, and Geert Deconinck. Cluster Control of Heterogeneous Thermostatically Controlled Loads Using Tracer Devices. IEEE Transactions on Smart Grid, 8(2):528-536, 2015. ISSN 1949-3053. doi: 10.1109/TSG. 2015.2483506 .

[42] Poul Alberg Østergaard and Henrik Lund. A renewable energy system in Frederikshavn using low-temperature geothermal energy for district heating. Applied Energy, 88(2):479 - 487, 2011. ISSN 03062619. doi: https://doi.org/10.1016/j.apenergy.2010.03.018. The 5th Dubrovnik Conference on Sustainable Development of Energy, Water and Environment Systems, held in Dubrovnik September/October 2009.

[43] Khalid Elgazzar, Howard Li, and Liuchen Chang. A centralized fuzzy controller for aggregated control of domestic water heaters. In Canadian Conference on Electrical and Computer Engineering, pages 11411146, St John's, NL, Canada, 2009. IEEE. doi: 10.1109/CCECE.2009. 5090304 .

[44] H Zhao, J Holst, and L Arvastson. Optimal operation of coproduction with storage. Energy, 23(10):859 - 866, 1998. ISSN 0360-5442. doi: http://dx.doi.org/10.1016/S0360-5442(98)00038-3.

[45] Clara Verhelst, Filip Logist, Jan Van Impe, and Lieve Helsen. Study of the optimal control problem formulation for modulating air-to-water heat pumps connected to a residential floor heating system. Energy and Buildings, 45:43-53, feb 2012. ISSN 03787788. doi: 10.1016/j.enbuild. 2011.10.015. 
[46] R. Baetens, R. De Coninck, J. Van Roy, B. Verbruggen, J. Driesen, L. Helsen, and D. Saelens. Assessing electrical bottlenecks at feeder level for residential net zero-energy buildings by integrated system simulation. Applied Energy, 96:74 - 83, 2012. ISSN 0306-2619. doi: http://dx.doi. org/10.1016/j.apenergy.2011.12.098.

[47] Jyri Salpakari, Jani Mikkola, and Peter D. Lund. Improved flexibility with large-scale variable renewable power in cities through optimal demand side management and power-to-heat conversion. Energy Conversion and Management, 126:649 - 661, 2016. ISSN 0196-8904. doi: http://dx.doi.org/10.1016/j.enconman.2016.08.041.

[48] Zhigang Li, Wenchuan Wu, Mohammad Shahidehpour, Jianhui Wang, and Boming Zhang. Combined heat and power dispatch considering pipeline energy storage of district heating network. IEEE Transactions on Sustainable Energy, 7(1):12-22, Jan 2016. ISSN 1949-3029.

[49] Dirk Vanhoudt, Bert Claessens, Johan Desmedt, and Christian Johansson. Status of the horizon 2020 storm project. Energy Procedia, 116:170 - 179, 2017. ISSN 1876-6102. doi: https://doi.org/10.1016/j.egypro. 2017.05.065. 15th International Symposium on District Heating and Cooling, DHC15-2016, 4-7 September 2016, Seoul, South Korea.

[50] Markus Falkvall and Viktor Nilsson. Optimerad framledningstemperatur i Lunds fjärrvärmenät. Master thesis, Lund Universitet, Sweden, 2013.

[51] A Bennonysson. Dynamic Modelling and Operation Optimization of District Heating Systems. PhD thesis, Technical University of Denmark (DTU), 1991.

[52] L. Saarinen. Modelling and control of a district heating system. Master thesis, Uppsala Universitet, Sweden, 2008.

[53] Henrik Gadd and Sven Werner. Achieving low return temperatures from district heating substations. Applied Energy, 136:59 - 67, 2014. ISSN 0306-2619. doi: https://doi.org/10.1016/j.apenergy.2014.09.022.

[54] Thomas Nussbaumer and Stefan Thalmann. Status Report on District Heating Systems in IEA Countries. Number December. 2014. ISBN 3908705282. 
[55] Tingting Fang and Risto Lahdelma. State estimation of district heating network based on customer measurements. Applied Thermal Engineering, 73(1):1211 - 1221, 2014. ISSN 1359-4311. doi: http: //dx.doi.org/10.1016/j.applthermaleng.2014.09.003.

[56] Fredrik Wernstedt and Paul Davidsson. An agent-based approach to monitoring and control of district heating systems. In International Conference on Industrial, Engineering and Other Applications of Applied Intelligent Systems, pages 801-811, Cairns, Australia, 2002. Springer.

[57] Ruben Baetens and Dirk Saelens. Modelling uncertainty in district energy simulations by stochastic residential occupant behaviour. Journal of Building Performance Simulation, 9(4):431-447, 2016. doi: 10.1080/19401493.2015.1070203.

[58] Svend Frederiksen and Sven Werner. District heating and cooling. chapter 9, pages 390-392. Studentlitteratur, 2013.

[59] Atli Benonysson, Benny Bøhm, and Hans F. Ravn. Operational optimization in a district heating system. Energy Conversion and Management, 36(5):297 - 314, 1995. ISSN 0196-8904. doi: http://dx.doi.org/ 10.1016/0196-8904(95)98895-T.

[60] Halldór Pálsson, Helge V. Larsen, Benny Bøhm, Hans F. Ravn, and Jijun Zhou. Equivalent models of district heating systems for on-line minimization of operational costs of the complete district heating system. Number 1323. 1999. ISBN 87-7475-221-9.

[61] Bram van der Heijde, Arnout Aertgeerts, and Lieve Helsen. Modelling steady-state thermal behaviour of double thermal network pipes. International Journal of Thermal Sciences, 117:316 - 327, 2017. ISSN 1290-0729. doi: https://doi.org/10.1016/j.ijthermalsci.2017.03.026.

[62] Helge V. Larsen, Halldór Pálsson, Benny Bøhm, and Hans F. Ravn. Aggregated dynamic simulation model of district heating networks. Energy Conversion and Management, 43(8):995 - 1019, 2002. ISSN 0196-8904. doi: http://dx.doi.org/10.1016/S0196-8904(01)00093-0.

[63] Fjo De Ridder and Mathias Coomans. Grey-box model and identification procedure for domestic thermal storage vessels. Applied Thermal 
Engineering, 67(1):147-158, jun 2014. doi: 10.1016/j.applthermaleng. 2014.03.003.

[64] C. Verhelst, G. Vandersteen, J. Schoukens, and L. Helsen. A linear dynamic borehole model for use in model based predictive control. In International Conference on Energy Storage, Effstock, Stockholm, Sweden, 2009.

[65] Bram van der Heijde, Edorta Carrascal Lecumberri, and Lieve Helsen. Experimental Method for the State of Charge Determination of a Thermally Activated Building System (TABS). In Proceedings of the Greenstock 13th International Conference on Energy Storage, Beijing, 2015.

[66] John Clauß, Christian Finck, Pierre Vogler-Finck, and Paul Beagon. Control strategies for building energy systems to unlock demand side flexibility-a review. In IBPSA Building Simulation 2017, San Francisco, 7-9 August 201\%. IBPSA, 2017.

[67] Anna Magdalena Kosek, Giuseppe Tommaso Costanzo, Henrik W. Bindner, and Oliver Gehrke. An overview of demand side management control schemes for buildings in smart grids. In 2013 IEEE International Conference on Smart Energy Grid Engineering (SEGE), pages 1-9, Oshawa, ON, Canada, 2013. ISBN 978-1-4799-2775-3. doi: 10.1109/SEGE.2013.6707934.

[68] Benny Bøhm, Seung-kyu Ha, Won-tae Kim, Bong-kyun Kim, Tiina Koljonen, Helge V. Larsen, Michael Lucht, Yong-soon Park, Kari Sipilä, Michael Wigbels, and Magnus Wistbacka. Simple models for operational optimisation. IEA District Heating and Cooling, Annex 6, 2002.

[69] Michał Leśko and Wojciech Bujalski. Operational optimization in district heating systems using thermal inertia of buildings. Rynek Energii, 2016.

[70] Leo Laakkonen. Predictive supply temperature optimization of district heating networks. In The 15th International Symposium on District Heating and Cooling, Seoul, Korea, 2016.

[71] Enso Ikonen, Istvan Selek, Jeno Kovacs, Markus Neuvonen, Zador Szabo, Jozsef Bene, and Jani Peurasaari. Short term optimization of dis- 
trict heating network supply temperatures. In IEEE International Energy Conference (ENERGYCON), pages 996-1003, Dubrovnik, Croatia, 2014. IEEE.

[72] Håkan Runvik, Per-Ola Larsson, Stéphane Velut, Jonas Funkquist, Markus Bohlin, Andreas Nilsson, and Sara Modarrez Razavi. Production planning for distributed district heating networks with JModelica.org. In Proceedings of the 11th International Modelica Conference, Versailles, France, September 21-23, 2015, number 118, pages 217-223. Linköping University Electronic Press, 2015.

[73] S. Grosswindhager, A. Voigt, and M. Kozek. Predictive control of district heating network using fuzzy DMC. In 2012 Proceedings of International Conference on Modelling, Identification and Control, pages 241-246, Wuhan, China, June 2012.

[74] F. Verrilli, S. Srinivasan, G. Gambino, M. Canelli, M. Himanka, C. Del Vecchio, M. Sasso, and L. Glielmo. Model predictive control-based optimal operations of district heating system with thermal energy storage and flexible loads. IEEE Transactions on Automation Science and Engineering, 14:547-557, 2017. ISSN 1545-5955. doi: 10.1109/TASE.2016. 2618948.

[75] B. Österlind. Effektbegränsning av fjärrvärme. In Rapport 63. 1982. ISBN 91-50-3714. Byggsforskningsområdet.

[76] Johan Kensby. Buildings as thermal energy storage Pilot test and largescale implementation for district heating systems. PhD thesis, Chalmers University of Technology, 2015.

[77] Fredrik Wernstedt and Christian Johansson. Intelligent distributed load control. In The 11th International Symposium on District Heating and Cooling, Reykjavík, Iceland, 2008.

[78] Ólafur Pétur Pálsson. Stochastic modelling, control and optimization of district heating systems. PhD thesis, Technical University of Denmark, Department of Applied Mathematics and Computer Science, 1993.

[79] N. Papakonstantinou, J. Savolainen, J. Koistinen, A. Aikala, and V. Vyatkin. District heating temperature control algorithm based on short 
term weather forecast and consumption predictions. In 2016 IEEE 21st International Conference on Emerging Technologies and Factory Automation (ETFA), pages 1-8, Berlin, Germany, Sept 2016. doi: 10.1109/ETFA.2016.7733748.

[80] Jan van Deventer, Jonas Gustafsson, and Jerker Delsing. Controlling district heating load through prices. In 5th IEEE International Systems Conference, SysCon 2011, Montreal, Canada, 2011. IEEE.

[81] Davy Geysen, Paul Booij, and Cor Warmer. A framework for simulation and control of hybrid energy networks. In 2014 IEEE International Energy Conference (ENERGYCON), pages 989-995, Cavtat, Croatia, 2014. IEEE.

[82] Felix Bünning, Michael Wetter, Marcus Fuchs, and Dirk Müller. Bidirectional low temperature district energy systems with agent-based control: Performance comparison and operation optimization. Applied Energy, 209:502 - 515, 2018. ISSN 0306-2619. doi: https://doi.org/10.1016/j. apenergy.2017.10.072.

[83] Christian Johansson, Markus Bergkvist, Davy Geysen, Oscar De Somer, Niklas Lavesson, and Dirk Vanhoudt. Operational demand forecasting in district heating systems using ensembles of online machine learning algorithms. Energy Procedia, 116:208 - 216, 2017. ISSN 1876-6102. doi: https://doi.org/10.1016/j.egypro.2017.05.068. 15th International Symposium on District Heating and Cooling, DHC15-2016, 4-7 September 2016, Seoul, South Korea. 